\title{
Collaborations and Design Development of Local Craft Products: Service Design for Creative Craft Community
}

\author{
Rasa Suntrayuth \\ Silpakorn University
}

\begin{abstract}
Local craft product is one of the key elements in expressing different identities of local culture in different countries. Local craft communities in Thailand have quite unique skills in producing different craft using local materials and techniques. However, the craft production is later facing the problem of missing their own identity. The products are also unable fit to the demand of international market.

This research is a result of the co-creation project on developing local craft products which is a part of the research on a service design for creative craft community: A case study of Phanusnikom district, Chonburi province, Thailand. The benefits of this study will stimulate the development and preservation of local craft products and communities in a more sustainable way. This study aims to explore the possible methods of how designers, local craftsmen, academic institutions and local business clusters can collaborate and raise new opportunities for the communities to become a creative craft space. The study has concentrated on a case study of Phanusnikom District, Chonburi Province, Thailand where most of the people are creating wickerwork from bamboo.

The data collected within the research come from ethnographic fieldwork, which consists of basic methods such as site visits and interviews. The research also includes the concept of Service design thinking and tools, which can help to analyze the data into different sets of relationship between service users, service providers, and environment. Groups of product design students, local craftsmen, local business clusters, professional designers, and artists are co - creating new craft products. The results express throughout the process which emphasize on presenting the ability of local craftsmen beyond what they are expected; exchanging knowledge; creating a more comfortable collaboration between the stakeholders; and strengthen the local craft community for more future sustainable developments.
\end{abstract}

Keywords: product design, service design, local craft community, craft development

\section{INTRODUCTION}

Craft usually refers to products, which are produced either completely by hand or with the help of tools. Mechanical tools may be used as long as the direct manual contribution of the artisan remains the most substantial component of the finished product. They are made from raw materials and can be produced in unlimited numbers. Such products can be utilitarian, aesthetic, artistic, creative, culturally attached, decorative, functional, traditional, religiously and socially symbolic and significant (UNESCO, 2009). Craft products are the community and the country pride as they are the trace of cultures, intellectuals, wisdoms, and aesthetics. They reflect 
ways of life of people who are living in the areas. Each local area in Thailand, people are creating unique craft products. They started from realizing of how abundant of raw materials they have which can create products that distinctive from other areas, from only a household product to be a national identity product. Local craft communities in Thailand are vast and diverse. Craft productions can provide opportunities for employment and lead to Thailand economic growth (Lisuwan, 1986).

Craft practices can be found in every part of Thailand. Many provinces have communities that are capable of making very outstanding and unique crafts. The majority of the craftspeople are working at home. When a community becomes a craft community, it contains with a lot of houses in the community that are working in the same craft productions. People get together into small groups and designate a leader who has more connections outside the community, in order to build up strength and get large orders. The leader works quite different roles, for instances, as a group manager; a product designer and a developer; and even a marketer who plans out marketing strategies to achieve their business success. The management of the local craft communities in many areas is quite similar. The leader of the group manages to get order from outside the community or even outside the country. The leader can also control the design as well as how the work should be done. The Government organizations come to help to promote and to support the communities but might not meet what the communities really need.

There are some attempts to improve craft productions and local craft communities in Thailand. Many districts are trying to create their own distinctive craft traditions. One Tambon (Sub-district) One Product program (OTOP) has started by the government in 2001. The OTOP program was inspired by a Japanese regional development program - The One Village One Product Movement (OVOP) which began in Oita Prefecture in 1979 (Natsuda et. al., 2015). It was intending to support local products in each subdistrict in Thailand. Different levels of product qualities receive different number of stars. It starts from one star to five stars for superior products. Consumers can be sure of the quality of anything awarded this level. The principles of OVOP as well as the OTOP are 1) Elevating local products to a global standard;

2) Providing self-reliance and creativity for people in the local communities; and 3) Developing human resources. However, the Thai OTOP program has unfortunately not been successful in a long run as it was one the political ploys in order to gain popularity from grass-root people (Chotiratanapinun, 2015). There were also so many corruptions going on at that time. The program's name is later changed but the OTOP brand was kept and used until now.

Phanusnikom district is the main focus of this research. It is in Chonburi province, which is located in the Eastern region of Thailand. It is famous for their bamboo wickerwork. The craft production of Phanusnikom started at the same time as when the community started to settle in the area. The original populace of Phanusnikom was mostly from The Laos Kingdom once it was governed by the monarchy (Phanusnikom Municipal, 2012). In the past, craft products were made to use within the household, for examples, a rice container, a fishing equipment, or a hat. They made them when 
they had a free time after harvesting rice. The knowledge has inherited from their ancestors along with their profession of agriculture. The craft products are later created for a more commercial activity. They are made to sell within the community, as the occupations of local people are now various. They also sell their craft products outside the communities and even outside the country. They have products from normal household objects to very delicate, luxury expensive products, such as, handbags and furniture. Another reason why Phanusnikom has became quite well known is how during the mid-year season, they have a festival called "Boon Klang Ban". The festival is basically made to respect to the nature for giving the locals opportunities to grow better crops with enough water and sunlight. This festival does not only appear in Phanusnikom but also in many communities in the Eastern and Central region of Thailand. However, Phanusnikom creates quite a unique festival by putting up a contest on the most beautiful and the biggest bamboo wickerwork. That was why Phanusnikom has got the name "The Biggest Bamboo Wickerwork Community" (Phanusnikom Municipal, 2009).

Phanusnikom bamboo wickerwork used to have quite a unique identity. They were trying to design weave patterns of their own. The patterns represent the outstanding features, which connect to people way of life and the culture of the community. The raw material was abundantly found within the community itself. Local people lived absolutely a self-sufficient life.

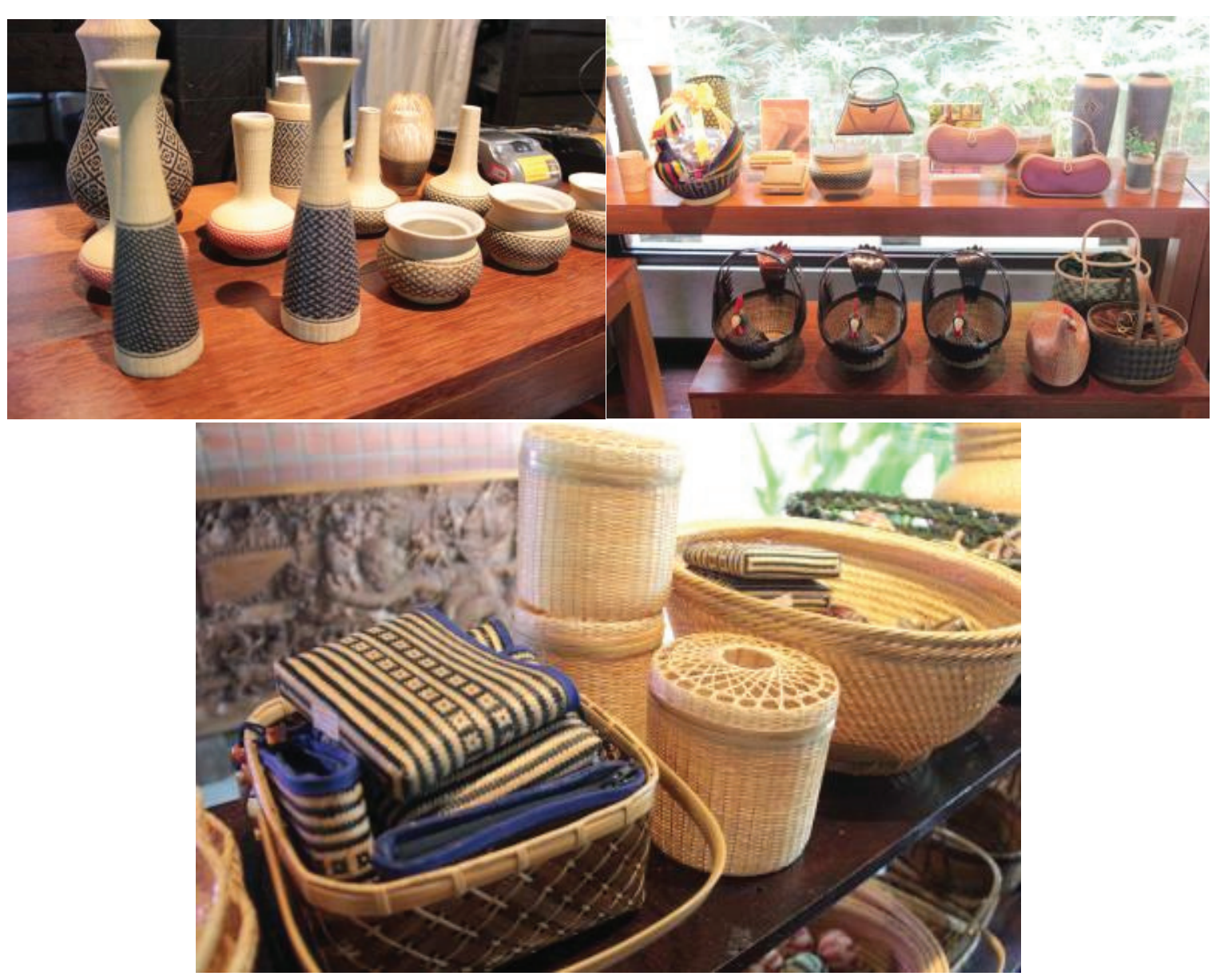

Figure 1: Images show Phanusnikom bamboo wickerwork. Source: http://nwnt.prd.go.th/ 
However, the way Phanusnikom community does their business has changed according to the global economic current. Local people started to produce fast and easy to sell products. It makes every shop and every sub-community in Phanusnikom district to sell products that look exactly the same. This problem is one of the main problems that other craft communities are having as well. When travelling to the craft community, there is no excitement going from one shop to another due to the lack of variety in the design of their products. The craft products are missing their own identity and also unable fit to the demand of international market, as well as, the demand of the modern life style. Moreover, the number of Phanusnikom craftsmen had gradually decreased. The knowledge is not easily transfer to people who want to learn. The knowledge of making craft is view as tacit knowledge, where specialized skills are embedded in a person or within a local community. The tacit knowledge possessed by the local artisans is acquired through extensive experience of working with materials and processes and it can primarily be acquired by practical and personal contact between master and apprentice (Polanyi, 1997) (Fang, 2012). Local people in Phanusnikom community form small groups in order to produce and to sell their products themselves as mention before. Every group is able to create almost every part of the products but one thing they cannot do well enough to export their bamboo baskets outside the country is the basket rim. Only one person in Phanusnikom community is able to do it well. Though, he is trying to transfer his knowledge to the younger generation but it is not a very easy thing to do. Learning craft needs a lot of attentions and it is quite time consuming to practice. Due to the modernization phenomenon, younger generation tends to move and work outside the community. As a result, the transmission of knowledge on craft is not as good as it should be.

\section{RESEARCH OBJECTIVES}

This research is a result of the co - creation project on developing local craft products which is a part of the research on a service design for creative craft community: A case study of Phanusnikom district, Chonburi Province, Thailand. It is an example case that further develops from the result of the previous research. This study is a practice-led research and it aims 1) to investigate the characteristics and relationship between different groups of stakeholders; 2) to explore methods in collaborating and developing new products in the most comfortable and sustainable ways for local craftsmen and stakeholders; and 3) to strengthen local craft community for a craft knowledge conservation and lead to the possibilities of being developed to a creative craft space.

\section{RESEARCH PROCESS}

As mention before, this research is a result of co-creation project represents a part of a research on a service design for creative craft community: A case study of Phanusnikom district, Chonburi province, Thailand. The main research is created to find out the potentials of local craft communities in Thailand and the possibilities for them to be developed in different facets. The research is based on an ethnographic 
approach and qualitative data collection. The ethnographic approach to qualitative research comes largely from the field of anthropology. The emphasis in ethnography is on studying an entire culture (William, 2006). It is the systematic study of people and cultures and designed to explore cultural phenomena where the researcher observes society from the point of view of the subject of the study. (Fetterman, 2009) The ethnographers rely on participant observation to gather data. As a participant observer, the ethnographer is socially and physically immersed in the case to accumulate local knowledge. (Parthasarathy, 2008) The research also includes the concept of service design thinking and tools, which can help to analyze the data into different sets of relationship between service users, service provides, and environment. Service design is an interdisciplinary approach that combines different methods and tools from various disciplines. It is a new way of thinking as opposed to a new standalone academic discipline. Service design is an evolving approach, this is particularly apparent in the fact that, as yet, there is no common definition or clearly articulated language of service design. (Stickdorn and Schneider, 2011).

Within this study, the process is separated into five phases as following; 1) Contextual Understanding phase is the starting of the whole process. The main idea of this step is to understand the context of the subject and other subjects that related. The methods used in this step are observation, literature review, case studies, trend studies, and semi-structure interview which is a bit more open and allow problems and new ideas to be brought up during the interview; 2) Field Research phase is how the researcher initiates field research and gather all the information. Field research step consist of different service design techniques, for instances, service safari and semistructure interview. The interviews in this step consist with open-ended questions within the space and see what happen and how the interviewees react during the interview. The questions are also focusing on getting into users' insights (five whys). After having all the data needed, the stakeholder maps, persona, and user journey maps are created to represent the relationship within the service; 3) Competitive Analysis phase is how the researcher identifies problems and sets up hypothesis for the solutions. The methods used within this step is focusing on idea generations, for instances, Brain storming, storytelling, case examples, and S.W.O.T analysis. After information is gathered, Kano analysis techniques is used to classify attributes based on how they are perceived by users and their effect on user satisfaction; 4) Design Development phase is how the information is analyzed and turned into different design developments, design concepts, service design blueprint, and strategic opportunities for the local craft communities to be developed to creative craft spaces; and lastly 5) Design Implementation phase is how to implement the concepts into a guideline for service design for local creative craft community. This paper is a part where the guideline is tested which concentrates on a small part within the human development on their design capability, particularly on craft product design and development. 


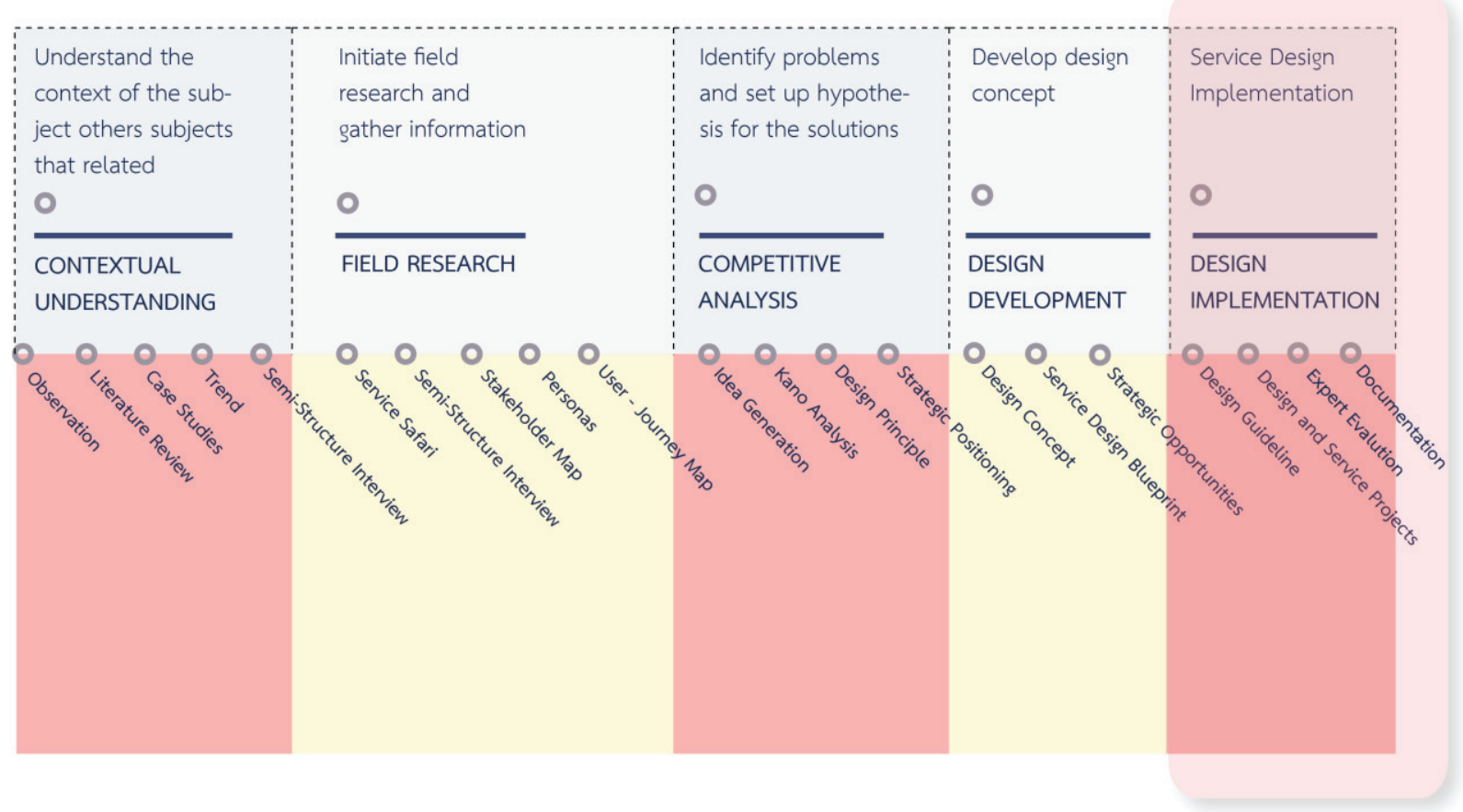

Figure 2: The diagram shows the five-research process phases and the pink color overlay represents the phase that this paper is on. Source: Rasa Suntrayuth

In Thailand, local craft community is one of the very important communities in the country in term of economics, which can create profits from the local craft products and creative tourism. Creative tourism program is also one of projects that Thai government found it has such an impact on economic and social development, as tourism is always a major economic factor in Thailand. In accordance with the definition given by the United Nations Educational, Scientific and Cultural Organization (UNESCO), Creative Tourism is a tourism related to community development for a sustainable way of life. The activities provided had to be harmonious and connected to history, culture and way of life in terms of learning and experience. Tourists gain experience and knowledge from the real life of the communities they visit. Additionally, communities had to set creative tourism as a tool for maintaining innovations for in-house tourism and benefits to communities in terms of economy and sustainable development. (Dasta, 2013). In consequence to the new tourism project that is made to reignite the growth of Thailand's tourist industry in a more profound way, local craft community becomes a place where people come and experience indigenous knowledge and local wisdom. Currently, a lot of people have realized the importance of knowledge and skills that are hidden in each local area. They are interested in the know-how and want use them in the creation of their own art and product design. Thus, there are quite often when artists, designers, and academic institutions around the area collaboratively work with the craftsmen within the local craft community.

With the initiated concept of preserving and developing craft product of Phanusnikom craft community, the information gathered within the phase two "field research" provided a map called "stakeholder map". A stakeholder map is a visual or physical 
representation of the various groups involved with a particular service. The interplay between these various groups can be charted and analyzed. (Stickdorn and Schneider, 2011) It is for the research team in planning for user research activities, and guiding appropriate communication with stakeholders throughout the project development process. (Martin and Hanington, 2012) It can also present the characteristics and relationship between different groups of stakeholders, which can answer the first objective of this paper.

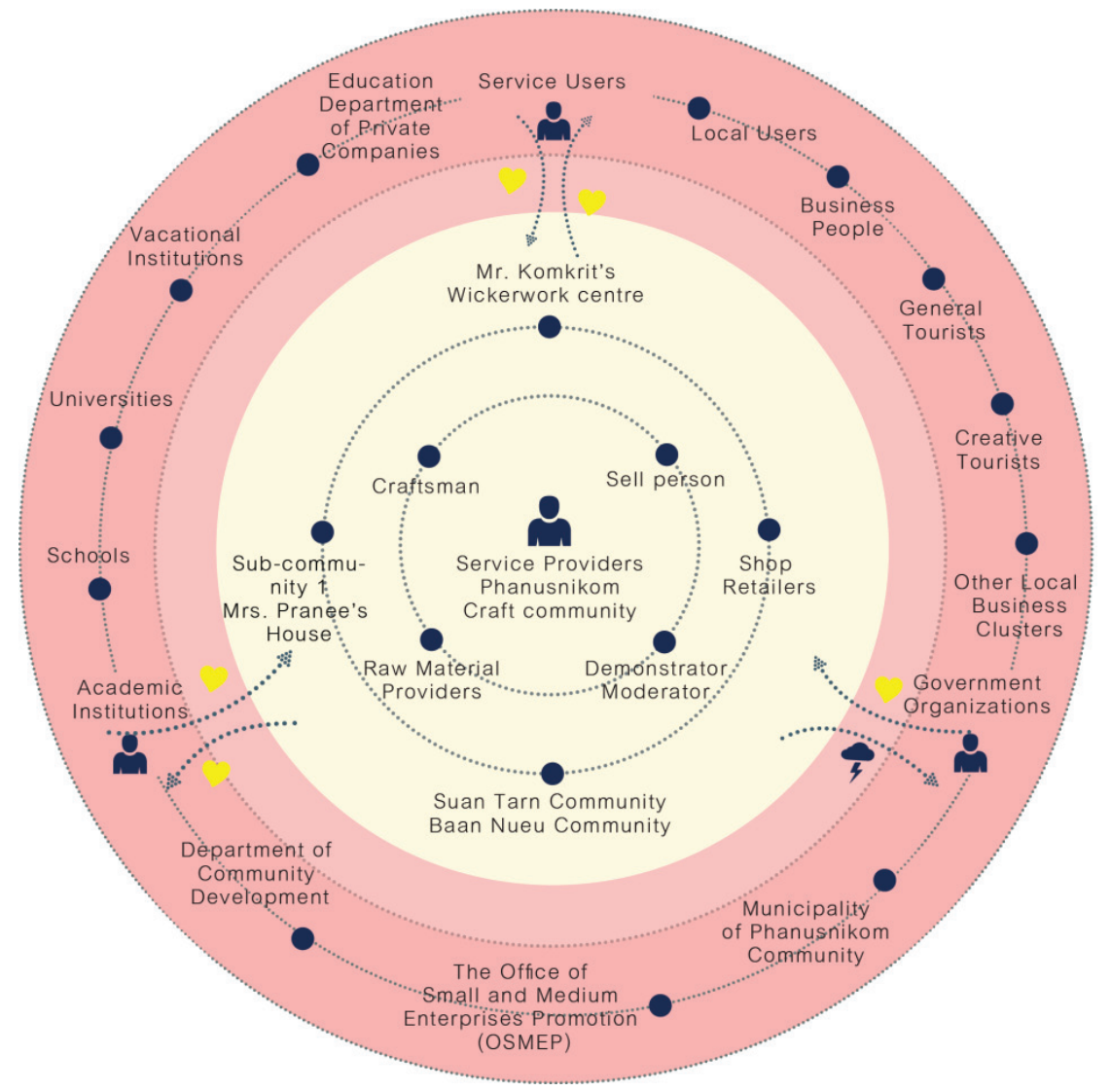

Figure 3: The diagram shows a stakeholder map of Phanusnikom craft community. Source: Rasa Suntrayuth

From Figure 3, the diagram explains the relationship between three groups of stakeholders. The first group is between Phanusnikom craft community and academic institution around the area. Their relationship goes quite well according to the activities they have together. Phanusnikom craft community, as mention before is an excellent place for students to come and learn from real experiences in many ways. They can provide wickerwork knowledge, techniques, and local materials. On the same hand, the academic institutions can also provide the local community knowledge on management, business, community development, and design thinking depend on the field they specialize at. The second group is Phanunikom craft community and customers (service users). Customers or service users which basically are separated into five groups which are 1) local users are people who live within the community and buy craft products and use them within their households; 2) business people who buy big bulks of craft products and sell them agian at their stores or export the products to other countries; 3 ) general tourists who travel to the local community for 
leisure purposes and happen to be interested into craft products or just buy them as souvenirs; 4) creative tourists who come to the local craft communities to learn and use the knowledge of craft making for their own creation. They usaully are designers, artists, and anyone who interested in taking craft product further; and 5) other local business clusters which are local people who do other businesses within the area, for instances, restuarents, coffee shops, spa products, and etc.. They sometimes use craft products to add more cultural values to their own products and make them more unqiue and interesting. Customers or service users are not expected much from the local community, they only want to experience the culture and buy the craft products. Thus, their relationship is quite settled. The last group is between Phanusnikom craft community and government organizations. The government organizations are not fully understand what the local craft community really needs. Therefore, the supports they have for the communities are not exactly help them in a long run.

According to the information from the stakeholder map, researcher is able to set up four different product design and development group projects. Each group is working within their own group to create new craft products by concerning about traditional craft techniques, sustainable and self-sufficient approaches for the locals. They are allowed to create their own design briefs and concepts according to the information they have. The four groups are 1) a group of third year product design students and local craftsmen; 2) a group of third year product design students and local business cluster which is Baan Ngam bath and spa products; 3) a group of third year product design students, a group of third year community development students and local young generations (with the age between 18 - 20 years old, university education) within the community; and 4) professional designers, researchers, and artists. The product design students, community development students, and local young generations are from the universities around the area of Phanusnikom community, which are Burapha University, and Rajabhat Rajanagarindra University. Therefore, they are quite familiar with the community itself.

Before the design and development projects started, the participants got to visit the local craft community, learned about their products and history, and had a small workshop of basic bamboo weaving. The first group of product design students spent more time visiting the craft community, interviewing craftsmen and retailers, observing the craft production process, conducting a bamboo wickerwork workshop, and visiting the bamboo fields to see how the raw material is processed. The second group of product design students spent a bit more time working with Baan Ngam bath and spa products. They had an extra task to understand Baan Ngam products and their markets in order to pick out suitable products and design new packaging for them. The third group of product design students joined up with community development students and local students. Their mission is to find a more fun and excitement point of view from people in younger generation. And lastly, the fourth group consisted with professional designers, researchers, and artists from different backgrounds. They spent different among of time in the community but likely to be less then other groups due to the limit of their time. The local craft community culture and style also have less influence over their designs. 


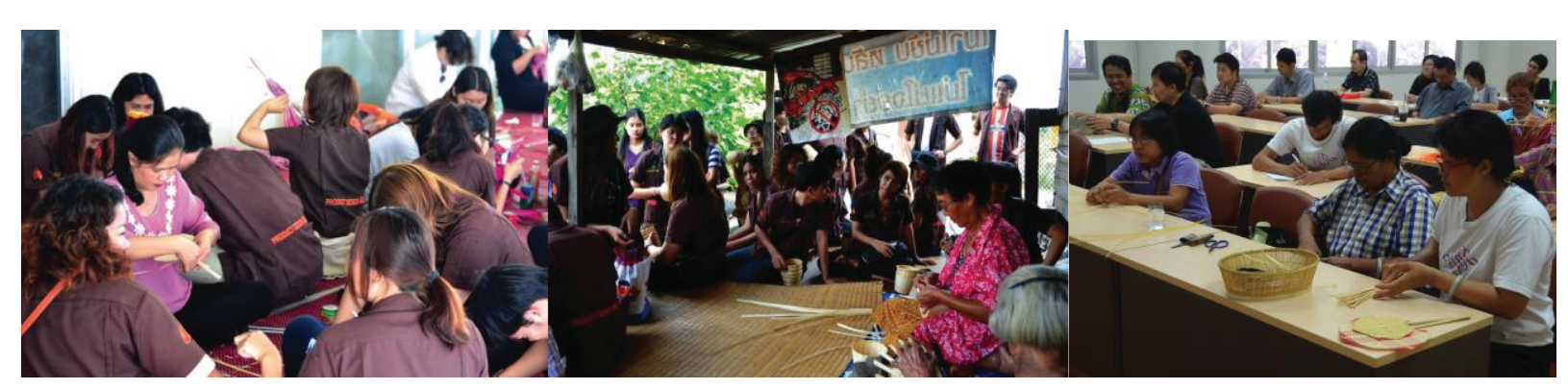

Figure 4: Images show local craft community study field trips and workshops. Source: Rasa Suntrayuth

\section{PRODUCT DESIGN OUTCOMES}

To create new products for the local craft community, home décor, personal accessory products, and packaging were proposed. The outcomes are quite varied due to their different design intentions and approaches. The first group of product design students and local craftsmen were working together in order to exchange new knowledge. Local craftsmen introduced the information on the material, weaving techniques, and local traditional wickerwork that they have been producing for many decades. Product design students introduced design thinking and new perspectives to the local craftsmen. They came up with the idea of creating home decoration products that adapted their forms from the traditional wickerwork they used to use in their everyday life, such as, rice and dried food containers, fishing traps and equipment. They wanted to preserve the traditional forms and styles and at the same time, to add new functions to the new products. For the production process, these designs are created to be easy to produce in order to capture the attention of the new generation craftsmen who think that working with craft is too difficult to start. The new products are simple but can represent the craftsmanship and cultural wisdom of Phanusnikom community.

The design outcomes from the second group of product design students and local business of Baan Ngam bath and spa products are quite different from the first group. As mention before, the young designers were not only explore the Phanusnikom craft products but also need to understand very well about the products of Baan Ngam bath and spa. They had to be able to design and apply wickerwork into packaging that suitable for the physical and the emotional of Baan Ngam bath and spa products. The bath and spa products that were selected to be redesigned were best seller products of Bann Ngam brand, such as, a bergamot shampoo, some herb soap, oil and incent burner set, and product gift set. The design brief was also to create more cultural uniqueness and add more value to the products. The outcomes were quite easy to produce. The new packaging designs brought up the dominant features of both Baan Ngam products and the wickerwork of Phanusnikom community. It was an interesting way to bring all the local businesses within the community together and that can lead to a more development in a bigger picture as a creative craft community in the future.

The third group of product design students, community development students, and the local young generations were working to create new lines of fashion and home 
accessories. Apart from learning and experiencing the local ways of life and how they create their craft products, this group of students was working together and presented their perspective about product design and development to the group. The product design students presented their idea in terms of design. The community development students presented their idea of producing products in the way to help develop the community in a more sustainable way. The students who lives within the local community presented the perspective of a user and how they familiar with seeing their parents making craft products since they were little. The activity was mainly storytelling and listing what their ideas were. The product design students took all the idea and designed products according to the information they have. As they are all new generation, their design brief was more to change up the group of target audience to be a little bit younger than it used to be.

Lastly, the groups of designers and artists from different backgrounds were working on their personal interests and specialty. Local craftsmen were only producing what designers and artists planned for them to do. Local craftsmen did not exactly affect the designers and artists in terms of their opinions. However, the concept of culture and how the locals work with material can inspired them in some ways. The outcomes from this group are totally varied. The shapes, forms and functions are somewhat different from what the local craftsmen have done before. The local craftsmen were not familiar with the designs they had to produce, which make it a little confuse and difficult for them to do at first. Nonetheless, it was an opportunity for them to learn and experience new things, which can actually remind them of the potential they have.

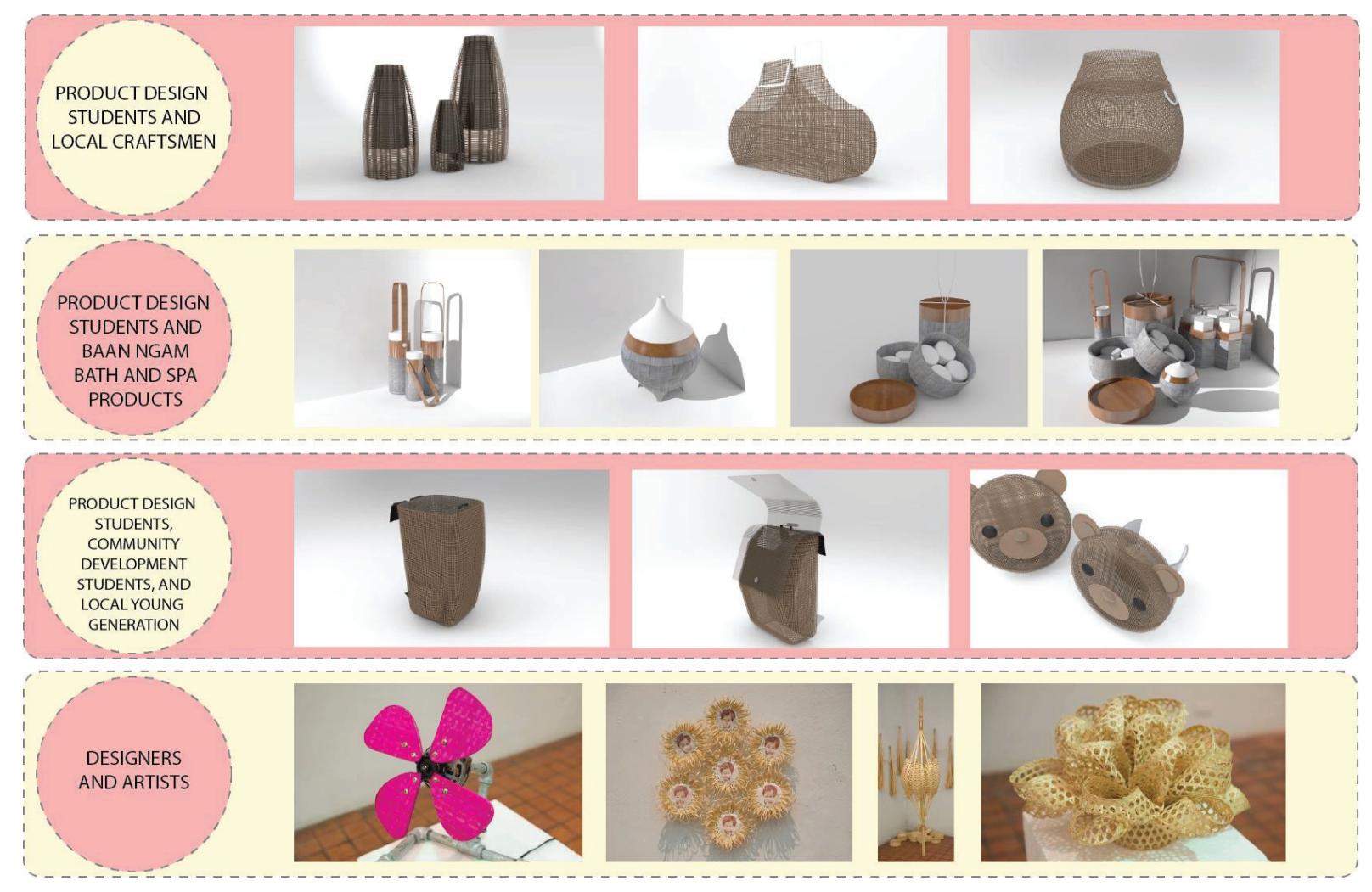

Figure 5: Images show product outcomes from different design groups. Source: Rasa Suntrayuth 


\section{DESIGN DIRECTIONS AND COLLABORATIONS}

Working in a local craft community and understanding the local setting, skills, materials, and products are somewhat very important. It is one of the main activities in the collaboration process. This understanding would help designers to get information in order to identify main problems and explore for more opportunities. During the collaboration process, designers can act as connectors and facilitators to connect and transfer ideas, knowledge, and skills into products. The project was quite challenge to the stakeholders in many ways. Students and academic institutions get to have opportunities to learn from the real experience. At the same time, local craftsmen and the community get to explore design knowledge during the project. Moreover, as the other local businesses like Baan Ngam get to participate in one of the design projects, apart from the new packaging designs that they get, they also gets a chance to interact to each other within the community, create a good vibe and relationships which can benefit to everyone. It can also strengthen the local community for more future sustainable developments.

This similar strategy also has happened in some other local craft communities. One of the very famous pottery communities of Thailand is in Ratchaburi province. Their handmade ceramic water jars with dragon patterns have been using in Thai household for so long. Rachaburi has a very nice consistency of soil that can create a very durable ceramic. Wasinburee Supanichvoraparch is a fourth generation of his family business from China - Tao Hong Tai ceramic factory. He was educated in Germany for his master's degree in fine arts and returned to his hometown- Ratchaburi Province after he graduated. He realized that water jar production know-how was not a family secret any more. The whole community in Ratchaburi is making the same exact products. (Chinmaneevong, 2013) The factory under the management of Wasinburee is opened for trainees and designers to use the studio and display their works at its showroom. With the idea of bringing designers and artists to the local community, can actually open the local craftsmen to some new perspective on design and lead them to shift from the conventional ceramics model of copying popular products to focus on original designs. Moreover, with different activities he creates for the local community, it can pull the people together and push forward Ratchaburi province to be an art city in the future.

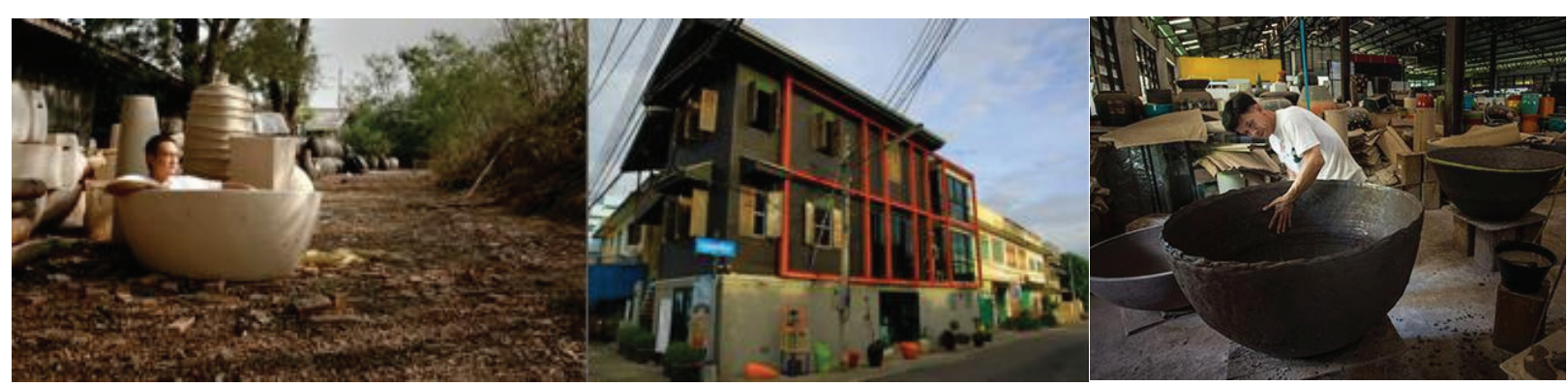

Figure 6: Wasinburee Supanichvoraparch,Tao Hong Tai Ceramics Factory and d Kunst Gallery-the first contemporary art gallery in Ratchaburi province. Source: www.tcdc.co.th, www.drphot.com, www. tatnews.org 


\section{CONCLUSION}

As mention before, local craft communities in Thailand are playing as an important role in terms of economic and cultural representative of the country. However, they recently have been facing different problems of losing the interestedness and excitement in their products and tourism.

Local people are moving out of the community to do something else rather then making craft products. The methodologies used within this project can bring people back to the community to work together. The collaboration provided local craftsmen and their stakeholders with an opportunity to learn and gain new experiences, which can lead them to become a creative craft center as mention earlier in the article. The knowledge and experiences gained from this study can be as a model, which can be applied by other practitioners for further research developments as well.

\section{REFERENCES}

Chinmaneevong, W. (2013). Bangkok Post article. Retrieved May 5, 2015, from http://www. bangkokpost.com/print/337696/

Chotiratanapinun, T. (n.d.). The emergence and existence of sustainable craft practices: Case studies from Indonesia and Thailanders. Retrieved May 1, 2015, from http://mfarchive. plymouthart.ac.uk/journalvol1/papers.php

DASTA. (2013). Creative Tourism Thailand. Retrieved March 24, 2015, from http:/ /www.dasta. or.th/creativetourism/attachments/article/112/20_9271 .pdf

Fang, W. (2012). Weaving with Rush: Exploring Craft-Design Collaborations in Revitalizing a Local Craft. Retrieved July 12, 2016, from http:/ / www.ijdesign.org/ojs/index.php/IJDesign/article/ view/1077

Fetterman, D. (2009). Ethnography: Step by Step, Third edition, Thousand Oaks CA, Sage. Lisuwan, Viboon. (1986). Thai Folk Crafts. Office of the National Cultural Commission, Thailand.

Martin, B. \& Hanington, B. (2012) Universal Methods of Design. Massachusetts: Rockport Publishers.

Natsuda, K., Wiboonoingse, A., Igusa, K., Cheamugphan, A., Shingkharat, S., \& Thoburn, J. (n.d.). One Village One Product - Rural Development Strategy in Asia: The Case of OTOP in Thailand. Retrieved May 1, 2015, from http://www.apu.ac.jp/

Parthasarathy, B. (2008). The ethnographic case study approach|The Global Impact Study.

Retrieved July 12, 2016, from http:/ /www.globalimpactstudy.org/2008/07/the- ethnographic-casestudy-approach/

Phanusnikom Municipal (2009). Sub-Community 1: The biggest Wickerwork in The world Publications. Chonburi: Ngan Chang Print and Media Company.

Phanusnikom Municipal, (2012). History of Phanusnikom Wickerwork: Phanusnikom Municipal Publications. Chonburi: Ngan Chang Print and Media Company.

Polanyi, M. (1997). The Tacit Dimension. In L. Prusak (Ed.), Knowledge in Organizations (pp. $135-$ 146). Newton, MA: Butterworth-Heinemann.

Stickdorn, M. \& Schneider, J. (2011). This is Service Design Thinking: Basics, Tools, Cases. New Jersey: John Wiley \& Sons, Inc.

UNESCO. (2009). Building confidence: Crafts for development. Retrieved July 12, 2016, from http:/ / portal.unesco.org/culture/en/ev.php- URL_ID=35418\&URL_DO=DO_TOPIC\&URL_ SECTION=201.html

William, M. K. (2006). Qualitative Approaches. Retrieved July 12, 2016, from http://www. socialresearchmethods.net/kb/qualapp.php 